\section{Modelos de atenção à saúde de usuários de álcool e outras drogas: discursos políticos, saberes e práticas}

\author{
Health care models for users of alcohol and \\ other drugs: political discourse, knowledge, \\ and practices
}

\author{
${ }_{1}^{1}$ Instituto de Saúde Coletiva, \\ Universidade Federal da \\ Bahia, Salvador, Brasil. \\ 2 Escola Estadual de Saúde \\ Pública, Secretaria de \\ Saúde do Estado da Bahia, \\ Salvador, Brasil. \\ Correspondência \\ V. S. Alves \\ Instituto de Saúde Coletiva, \\ Universidade Federal da \\ Bahia. \\ Rua Clóvis Spinola 40, Bloco D, \\ apto. 202, Salvador, BA \\ 40080-24, Brasil. \\ vaniasampa@yahoo.com.br
}

\section{Abstract}

This article aims to characterize health care models for users of alcohol and other drugs in the Brazilian context. Discourse analysis was performed on public drug policy in Brazil from the 1970s. This analysis was contextualized by a brief digression on the main political positions identified in several countries of the world in relation to drug use problems. Beginning in the current decade, drug policies in Brazil have been receptive to harm reduction approaches, resulting in reorientation of the health care model. In conclusion, the structuring and strengthening of a network of care for users of alcohol and other drugs and their families, based on community care and the harm reduction approach and combined with other social and health services, is now a key public health challenge for the country.

Alcoholism; Substance-Related Disorders; Harm Reduction; Public Policies
Vânia Sampaio Alves 1,2

\section{Introdução}

O debate em torno dos modelos de atenção à saúde tem problematizado a adequação das práticas e dos processos de trabalho à resolução dos problemas de saúde da população. Três dimensões têm sido contempladas nesse debate: a político-gerencial, a organizacional e a tecnológica 1 . A primeira corresponde à esfera de formulação e implementação de políticas. A dimensão organizacional refere-se às relações estabelecidas entre as unidades de saúde, que geralmente considera a hierarquização dos níveis de complexidade assistencial. A dimensão tecnológica contempla o conteúdo das práticas e a organização social dos processos de trabalho em saúde 2 .

Em conformidade com uma concepção sistêmica, a reorientação do modelo de atenção à saúde deve resultar da conjugação de propostas e estratégias sinérgicas nas três dimensões, ainda que mudanças parciais, operadas em dimensões isoladas, possam propiciar o desencadeamento de transformações mais amplas. Nesta perspectiva, depreende-se que a reorientação do modelo de atenção à saúde consiste em um processo extremamente complexo, cuja concretização exige tanto iniciativas nas esferas político-gerencial e organizacional quanto tecnológica 1. A formulação e implementação de políticas públicas, por exemplo, pode contribuir para a reprodução de um modelo de atenção à 
saúde hegemônico ou propiciar condições para a reinvenção das práticas e dos processos de trabalho em saúde.

O presente artigo tem por objetivo caracterizar os modelos de atenção à saúde de usuários de álcool e outras drogas existentes no contexto brasileiro. Para tanto, parte-se do pressuposto teórico de que das políticas públicas na área de álcool e outras drogas emanam as racionalidades ou lógicas que orientam as práticas de atenção em saúde. Em conformidade com este pressuposto, realizou-se uma análise do discurso das políticas públicas de drogas no Brasil. O corpus de análise 3 foi constituído pelo conjunto de leis, decretos, portarias, medidas provisórias e outros documentos relativos a tais políticas, editados no país a partir da década de 1970. Contextualizou-se a revisão das políticas públicas de drogas e caracterização dos modelos de atenção à saúde de usuários de álcool e outras drogas existentes no Brasil com uma breve digressão acerca dos principais posicionamentos políticos identificados entre países do mundo para o enfrentamento de questões relacionadas ao consumo de substâncias psicoativas. Espera-se, enfim, fomentar a discussão em torno da reorientação do modelo de atenção à saúde de usuários de álcool e outras drogas na realidade brasileira frente às recentes políticas públicas sobre drogas, sobretudo, as políticas de saúde.

\section{Discursos políticos e a construção dos modelos de atenção à saúde de usuários de álcool e outras drogas}

O consumo de substâncias psicoativas, desde civilizações antigas, sempre esteve sob regulação social. A princípio, a regulação se estabeleceu em contextos sócio-culturais específicos que condicionaram o consumo de determinadas substâncias mediante normas e convenções socialmente compartilhadas. O isolamento de princípios ativos de substâncias psicoativas e sua industrialização, a partir do século XIX, resultaram em formas de apresentação mais potentes. Este fato foi acompanhado por popularização crescente dessas substâncias e expansão de seu consumo com finalidade terapêutica e também recreativa. A expansão, entretanto, foi acompanhada pelo enfraquecimento das estratégias sócio-culturais de regulação do consumo das substâncias e da emergência de um conjunto de questões sociais e de saúde a ele associado ${ }^{4}$. Na ausência de um lastro cultural que contextualizasse o padrão contemporâneo de consumo de substâncias psicoativas, fez-se evidente a necessária intervenção reguladora do Estado, a qual tem se concre- tizado mediante a formulação e implementação de políticas públicas.

A revisão da literatura permite identificar dois principais posicionamentos políticos para o enfrentamento de questões relacionadas ao consumo de álcool e outras drogas: o proibicionismo e a abordagem de redução de danos 5,6,7. Enquanto as políticas proibicionistas concentram esforços na redução da oferta e da demanda de drogas, com intervenções de repressão e criminalização da produção, tráfico, porte e consumo de drogas ilícitas; as políticas e programas de redução de danos têm disseminado intervenções orientadas para a minimização dos danos à saúde, sociais e econômicos relacionados ao consumo de álcool e outras drogas sem necessariamente coibi-lo 7,8,9. Os pressupostos ideológicos bem como os benefícios e os danos associados às diferentes tônicas das políticas públicas sobre drogas têm fomentado um profícuo debate 10 , particularmente no que concerne ao modelo de atenção à saúde de usuários de álcool e outras drogas 7,8,11.

O proibicionismo constituiu-se no alicerce ideológico da política pública sobre drogas nos Estados Unidos 6,9,12,13. De acordo com Ribeiro \& Araújo 14, o movimento proibicionista em relação às drogas teve sua origem no início do século XIX, quando se observava o crescimento exponencial da industrialização de bebidas alcoólicas no país e, conseqüentemente, do seu consumo. Logo esta racionalidade se disseminou na sociedade norte-americana e, em 1869, foi fundado o Partido Proibicionista. A proibição da comercialização de bebidas alcoólicas tornou-se uma reivindicação ampla de segmentos daquela sociedade e culminou, em 1920, com a promulgação da Lei Seca, que conferiu ao álcool o status de droga ilícita naquele país, entre 1920 e 1932.

O discurso proibicionista, entretanto, não se restringiu à questão do consumo de álcool. Em conseqüência do aumento do consumo de ópio, os Estados Unidos lideraram a campanha pela supressão gradual do comércio internacional dessa substância, a qual desencadeou a realização de uma série de eventos internacionais para o debate em torno da questão - os Encontros de Xangai, em 1906 e 1911, e as Conferências em Haia, em 1912 e 1914. Convenções internacionais foram sendo firmadas para a repressão do comércio e o consumo de drogas - ópio, morfina, cocaína e toda substância que pudesse levar ao uso abusivo. Com grande apelo à adesão das nações, o discurso proibicionista conquistava hegemonia 14.

A fundação da Organização das Nações Unidas (ONU), em 1945, representa outro importante marco histórico para a consolidação de polí- 
ticas públicas sobre drogas de orientação proibicionista. Com a ONU, os debates em torno da questão das drogas foram reaquecidos no plano internacional. Em 1946, foi criada pela ONU a Comissão de Narcóticos (CDN), com a atribuição de formular políticas para o fortalecimento do sistema de controle e repressão internacional às drogas. A CDN organizou três Convenções Internacionais (Nova Iorque, 1961; Viena, 1971; Viena, 1988) - conhecidas como as Convenções-Irmãs da ONU - com o objetivo de construir um programa em relação à questão das drogas comum aos seus estados-membros. Para Ribeiro \& Araújo 14 (p. 462), “as Convenções-Irmãs da ONU estabeleceram o sistema internacional de combate das drogas, reafirmando o proibicionismo como a política a ser seguida por todas as nações".

Em 1998, a ONU convocou uma Sessão Especial da Assembléia Geral (UNGASS) para a discussão da política mundial de drogas. Este evento não apenas ratificou as Convenções-Irmãs como também estabeleceu a meta de erradicação do cultivo de plantas e vegetais para a produção de drogas ilícitas, uma estratégia considerada chave para a supressão do consumo de drogas ilícitas no mundo. O plano de ação da UNGASS estabelecia o ano de 2008 como prazo para o alcance dessa meta e intitulava-se Um Mundo Livre de Drogas: Nós Podemos Fazê-lo 12,14. Em 2003, tanto a meta quanto o prazo para atingi-la foram reafirmados pela ONU.

As contradições produzidas pelas políticas proibicionistas em relação às drogas são destacadas por muitos autores 6,9,10,12. Para Perduca 12 (p. 61), “o proibicionismo é um conjunto de leis e políticas que não deslancharam; na realidade, um conjunto de leis e políticas que falharam". As ações de repressão à produção, comércio e consumo de drogas ilícitas definitivamente não contiveram estes fenômenos em qualquer parte do mundo. Ao contrário, observou-se o crescimento do tráfico ilícito de drogas e de sua repercussão na política e na economia mundial 14,15. Em relação ao consumo, estudos epidemiológicos retratam o crescimento do número de usuários de drogas lícitas e ilícitas, com a facilidade de acesso propiciando o início cada vez mais precoce do uso na vida 9,16,17. A criminalização do porte e do consumo de drogas ilícitas tem se revertido em sobrecarga ao sistema de justiça, onerando-o tanto pela lotação de unidades prisionais quanto pelo aumento de investimentos financeiros para a militarização das ações policiais de "combate" às drogas 12 .

A ênfase na redução da oferta de drogas, por meio da criminalização tanto do tráfico quanto do uso de drogas ilícitas, conferiu uma importância secundária à redução da demanda promovida mediante as intervenções de prevenção e tratamento aos dependentes químicos. Estima-se que dos recursos financeiros da política de drogas norte-americana, menos de $10 \%$ sejam destinados às ações de tratamento 9,15,18. Esta talvez possa ser apontada como a mais profunda das contradições das políticas proibicionistas.

O proibicionismo encontra-se atrelado a dois modelos explicativos para a questão do consumo de drogas: o modelo moral/criminal e o modelo de doença 7,9,19. Para o primeiro, o consumo de drogas configura um problema moral, uma prática delituosa cujo enfrentamento consiste no encarceramento dos imorais/criminosos. O modelo de doença concebe o consumo de drogas e a dependência como uma patologia biologicamente determinada e, como tal, deve ser abordado com a oferta de tratamento e reabilitação ${ }^{19}$. Embora os modelos explicativos divirjam quanto às suas propostas de intervenção, ambos compartilham do propósito de eliminação do consumo de drogas - seja pelo encarceramento seja pelo tratamento. De acordo com uma perspectiva de não-tolerância às drogas, as ações de prevenção objetivam especialmente a redução da demanda por drogas e o tratamento admite a abstinência como única meta plausível.

A assistência à saúde ofertada segundo a perspectiva proibicionista tem sido caracterizada como de "alta exigência" 19. Destaca-se a indistinção feita pelos adeptos desta vertente entre o consumo de drogas ocasional daquele considerado abusivo e/ou prejudicial, caracterizado como um padrão de consumo capaz de produzir danos sociais e à saúde, inclusive a dependência química. Nenhum padrão de consumo é tolerado e a abstinência desponta como condição, meio e finalidade do tratamento: "A única meta aceitável de quase todos os programas de tratamento para alcoolismo e drogas nos Estados Unidos é a abstinência vitalícia, juntamente com atendimento contínuo em grupos de recuperação do tipo Doze Passos. Na verdade, a abstinência é quase sempre pré-requisito para o tratamento, uma vez que a maioria dos programas de tratamento de dependência química recusa-se a admitir pacientes que ainda estejam usando drogas. A exigência de que o indivíduo deve primeiro abster-se a fim de receber o tratamento que visa manter a abstinência exemplifica uma abordagem de "alta exigência", a qual muitas vezes torna-se um obstáculo para aqueles que procuram ajuda" 19 (p. 46).

Uma das limitações apontadas para o modelo de atenção à saúde baseado exclusivamente na abstinência refere-se ao fato de esta condição representar uma importante barreira ao acesso das pessoas que fazem uso prejudicial ou apresentam dependência de drogas às instituições de 
saúde 19. A alta exigência em torno da abstinência implica ainda censuras e recriminações aos episódios de recaída ou reincidência ao uso de drogas, tornando as instituições de saúde espaços pouco acolhedores àqueles estigmatizados como "fracos", "vagabundos", "sem-vergonha", "imorais".

O modelo de atenção à saúde de usuários de álcool e outras drogas construído com base na racionalidade proibicionista caracteriza-se, então, pelo autoritarismo das intervenções propostas. A criminalização dos usuários de drogas repercute na garantia de direitos sociais e de cidadania, dentre os quais o de livre acesso aos serviços de saúde e tratamento e mesmo o de fazer uso de drogas em condição não prejudicial ao indivíduo e à sociedade. A despeito das crescentes críticas a este modelo de atenção, ele mantém-se hegemônico nos Estados Unidos 6,9,13 e fortemente influente na Suécia, Japão, Cingapura, Malásia e alguns outros países asiáticos 20 .

A hegemonia do discurso político proibicionista em relação às drogas não impediu, contudo, a emergência de um enfoque político alternativo, contra-hegemônico 7,8. A este respeito, Ribeiro \& Araújo 14 (p. 464) pontuam que "historicamente, os países europeus sempre defenderam a redução da demanda como política preferencial, em detrimento de políticas fortemente centradas na redução de oferta". Ainda que tal enfoque político não seja consenso em toda Europa, esta se constituiu no berço da redução de danos como uma alternativa de saúde pública aos modelos de atenção fundamentados exclusivamente na abstinência 19,20. A Holanda e o Reino Unido desenvolveram iniciativas precursoras do modelo de redução de danos, que se consolidou, na década de 1990, pelo impacto produzido na prevenção de transmissão do HIV/AIDS entre usuários de drogas injetáveis (UDI) 8,11.

Os princípios da redução de danos se sustentam no pragmatismo de que o consumo de drogas sempre esteve e sempre estará presente na história da humanidade 7,8,11,19. Assim, o ideário de uma sociedade livre de drogas perde por completo o seu sentido. Se o consumo de drogas não pode ser suprimido da sociedade, é possível traçar estratégias para reduzir os danos a ele relacionados, tanto para os usuários quanto para a coletividade. Esse enfoque tem sido apontado como aquele que confere maior racionalidade ao enfrentamento da questão das drogas, propiciando, por exemplo, compreender o consumo de drogas como um problema de saúde pública e o tráfico como um problema jurídico-policial 7,9,11,19.

A reforma na política pública de drogas na Holanda teve início na década de 1970, desenca- deada pela constatação do aumento dos problemas relacionados às drogas em um país até então aderente ao discurso proibicionista e às medidas de repressão ao tráfico e ao consumo de drogas ilícitas. No ano de 1972, o Comitê de Narcóticos da Holanda publicou um documento que definia que a política de drogas deveria ser coerente com os riscos associados ao uso das drogas. Em 1976, foi aprovada a Lei Holandesa do Ópio, que distinguia as drogas de "risco inaceitável" à saúde (heroína, cocaína, anfetaminas e LSD) e as drogas de "menor risco" (maconha e haxixe). Com essa medida política, buscava-se proteger os usuários de drogas de "menor risco" ou "leves" dos ambientes de tráfico e das relações com os usuários de drogas "pesadas", pressupondo que tais relações poderiam conduzir o usuário de drogas "leves" ao consumo de substâncias mais prejudiciais. O comércio das drogas "leves" foi legalizado em espaços conhecidos como "cafeterias" (coffeeshops), onde a maconha ou o haxixe ali adquiridos podem ser consumidos no próprio local 19.

Na década de 1980, o movimento social de usuários e dependentes de drogas fundou, em Roterdã, a Liga de Dependentes ou Junkies (a Junkiebond), que passou a reivindicar melhorias das condições de saúde e de qualidade de vida dos usuários de drogas. Por intermédio desta organização política, estabeleceu-se a interlocução entre os usuários de drogas e o governo holandês com a discussão de questões como a disponibilização de seringas e agulhas esterilizadas e o tratamento de manutenção de metadona. Em 1984, foi lançado o primeiro programa de troca de seringas e agulhas em Amsterdã, que foi consideravelmente ampliado nos anos seguintes à medida que a epidemia da AIDS avançava e o risco de infecção pelo HIV, em decorrência do compartilhamento desses recursos entre os UDI, apresentava-se fortemente evidenciado 19. O êxito da experiência holandesa na diminuição de casos de infecção por HIV entre UDI contribuiu para a popularização da estratégia de redução de danos em outros países 8,11 .

No Reino Unido, as primeiras intervenções na área de saúde referidas como precursoras do movimento de redução de danos datam da década de 1920. Em 1926, um grupo de médicos recomendou a prescrição de drogas como a heroína e cocaína para usuários dependentes com o propósito de reduzir os danos de seu uso e assim melhorar a sua qualidade de vida. A prescrição de drogas não foi aprovada como uma política pública, predominando no país o enfoque proibicionista, mas continuou sendo praticada pelo Departamento de Saúde de Merseyside, que atendia à população da cidade de Liverpool. Com 
a epidemia da AIDS, na década de 1980, a prescrição de drogas para dependentes ganhou novo impulso como estratégia de redução de danos entre UDI 18,19,21.

A prescrição de drogas para dependentes como estratégia de redução de danos pauta-se em algumas premissas. Entende-se que a prescrição reduz os sintomas da abstinência e constitui uma espécie de atrativo ao tratamento oferecido aos usuários de drogas, contribuindo, inclusive, para a adesão a ele. Outra função atribuída a esta estratégia seria o estabelecimento de "metas intermediárias” no processo de mudança no padrão de consumo de drogas, de forma a reduzir gradualmente os danos relacionados. Para aqueles usuários dependentes que não podiam ou não desejavam alcançar a abstinência, a prescrição de drogas teria a função de lhe proporcionar redução de danos e qualidade de vida. De acordo com Fonseca \& Bastos 18, a prescrição de metadona contempla $98 \%$ dos usuários britânicos de heroína que realizam tratamento "não abstinente".

Se o movimento social dos usuários de drogas exerceu grande importância para a construção e consolidação do modelo holandês de redução de danos, o êxito da experiência inglesa tem sido remetido, em parte, à articulação estabelecida com a polícia 19,20. Esta, ao invés de restringir o seu papel à repressão ao consumo de drogas, passou a atuar em aliança e cooperação com os serviços de saúde, oferecendo apoio público aos programas de troca de seringas e encaminhando usuários infratores para tratamento. A articulação com a rede de farmácias para a distribuição gratuita de seringas e agulhas estéreis, ampliando o acesso dos usuários a esses recursos, também merece destaque pela sua relevância ao programa inglês de redução de danos. Para Marlatt 19, a organização política de usuários de drogas e a articulação do sistema de saúde com outros dispositivos e setores sociais são aspectos que caracterizam a redução de danos como uma política construída de "baixo para cima", tendo em vista que o desenvolvimento de programas de redução de danos local ou regional tem precedido, em muitos casos, a formulação de políticas públicas de drogas referenciadas em seus princípios.

Os receios que alimentaram desconfianças e resistências em relação às estratégias de redução de danos nos anos iniciais de sua implantação não foram confirmados. O aumento desenfreado do consumo de drogas ilícitas e a escalada do uso de drogas "leves" para as drogas "pesadas", por exemplo, são fenômenos não observados nos países e regiões que adotaram a perspectiva da redução de danos ${ }^{8}$. Em contrapartida, constata-se o aumento da demanda por tratamento entre usuários assistidos por programas comunitários de redução de danos e a ampliação do acesso a ações e serviços de saúde de um modo geral 19,20,22.

O tratamento orientado pela lógica da redução de danos é descrito como de "baixa exigência”, por não exigir dos usuários a abstinência como um pré-requisito obrigatório, o que não significa, todavia, que o enfoque da redução de danos contraponha-se à abstinência como um resultado ideal ao tratamento 13,19,23,24. Ao invés de estabelecer a abstinência como única meta aceitável da prevenção e do tratamento, a redução de danos concilia o estabelecimento de metas intermediárias. $\mathrm{O}$ foco desta abordagem está na adoção de estratégias para minimizar os danos sociais e à saúde relacionados ao consumo de drogas, mesmo que a intervenção não produza uma diminuição imediata do consumo. A atenção centra-se nas necessidades sociais de saúde do usuário, que precisa ser engajado de forma respeitosa no delineamento das metas para o tratamento buscado 7,19 .

As experiências em redução de danos nos países que têm assumido este enfoque na revisão de suas políticas públicas de drogas evidenciam a diversidade de intervenções possíveis para diminuir os danos que o uso de drogas pode acarretar ao usuário, a sua família e a comunidade em que vive 8 . Tal diversidade, por sua vez, mantém estreita relação com o contexto sócio-político e sanitário de cada país que adota políticas e programas de redução de danos. Ressaltam-se, ainda, as transformações culturais transversais a essas experiências, tendo em vista uma releitura social da questão das drogas e o reconhecimento do uso prejudicial e dependência como um problema de saúde pública. Os caminhos percorridos por cada país para a construção de um modelo de atenção à saúde de usuários de álcool e outras drogas podem, então, ser compreendidos como processos históricos singulares. Com base nesse pressuposto, passa-se à análise da experiência do Brasil na atenção às questões relacionadas ao consumo de álcool e outras drogas.

\section{Políticas públicas de drogas no Brasil: entre o discurso proibicionista e o enfoque da redução de danos}

O Brasil consta entre os países signatários das convenções internacionais para a repressão ao tráfico e ao uso de drogas ilícitas, o que repercutiu na formulação de uma política de drogas nacional alinhada ao discurso proibicionista 5,25,26. A partir da década de 2000, as políticas públicas de drogas brasileiras têm-se apresentado perme- 
áveis ao enfoque da redução de danos, favorecendo o delineamento de um modelo de atenção de usuários de álcool e outras drogas orientado por essa racionalidade 27,28 .

As primeiras intervenções do Estado brasileiro de repressão às drogas datam do início do século XX, quando a venda de ópio e seus derivados e de cocaína foi proibida e a pena de prisão prevista aos infratores 25 . Na década de 1920, a legislação penal propunha a internação compulsória em estabelecimento correcional adequado, por tempo indeterminado, dos denominados toxicômanos. Na década de 1930, foi promulgada a Lei de Fiscalização de Entorpecentes (Decreto-Lei $n^{o}$. 891/1938) que expressava claramente o posicionamento proibicionista do Estado brasileiro em relação às drogas. O conteúdo deste decreto-lei, posteriormente incorporado ao artigo 281 do Código Penal de 1940, criminalizava o porte de drogas ilícitas independentemente da quantidade apreendida e da intenção de consumo próprio ou tráfico, sem distinção da penalização prevista para uma ou outra circunstância 25,26. Na década de 1970, as medidas de prevenção e de repressão ao tráfico e uso de drogas ilícitas instituídas pela legislação brasileira estavam em plena concordância com as resoluções das duas primeiras Convenções-Irmãs da ONU, realizadas em 1961 e 1971.

No que concerne às intervenções de saúde, a Lei $n^{o}$. 5.726/1971 29 não faz qualquer referência ao tratamento para a população usuária de drogas, exceto daqueles referidos como "infratores viciados". Estes correspondiam àqueles que, em razão do "vício", não possuíam condições de discernimento acerca do caráter ilícito de seu ato ou de determinar-se de acordo com esse entendimento. Como medidas de "recuperação aos infratores viciados", previa-se a determinação judicial de "internação em estabelecimento hospitalar para tratamento psiquiátrico pelo tempo necessário à sua recuperação" (art. 10). Com esta medida, o que prevalecia não era o direito à saúde, com a garantia de tratamento à dependência de drogas, mas sim a "reabilitação criminal do viciado" (art. 13).

A Lei $n^{o} .6 .368 / 197630$ amplia, em certa medida, a abordagem sobre o tratamento e a recuperação de usuários de drogas. A assistência à saúde passa a ser considerada não apenas para os “viciados infratores", mas para os "dependentes de substâncias entorpecentes”. A lei afirma que as redes dos serviços de saúde dos Estados, Territórios e Distrito Federal contarão, sempre que necessário e possível, com estabelecimentos próprios para tratamento dos dependentes de substâncias entorpecentes ou que determinem dependência física ou psíquica. Em contraste com o discurso normativo da lei, a criação de serviços especializados para a atenção ao uso prejudicial e dependência de drogas não configura uma determinação legal, mas sim uma recomendação, fato que evidencia uma importância secundária às ações de saúde em detrimento à repressão da oferta/demanda de drogas.

Ainda em relação à atenção à saúde, a Lei $n^{\circ}$. 6.368/1976 detalha que "o tratamento sob regime de internação hospitalar será obrigatório quando o quadro clínico do dependente ou a natureza de suas manifestações psicopatológicas assim o exigirem" (art.10). O tratamento extra-hospitalar em serviços públicos ou privados estava previsto para os casos em que a internação não fosse necessária. A despeito da vigência da lei, os primeiros serviços extra-hospitalares especializados na assistência aos usuários de drogas ilícitas começaram a ser criados no Brasil somente na segunda metade da década de 1980 31. Considerando-se a lacuna da rede extra-hospitalar para esta atenção especializada e a restrição do acesso ao sistema de saúde aos contribuintes previdenciários, não é difícil entender que a internação em hospitais psiquiátricos tenha se constituído, naquele momento histórico, como único recurso terapêutico possível a uma importante parcela de usuários de álcool e outras drogas.

Na década de 1980, foi instituído o Sistema Nacional de Prevenção, Fiscalização e Repressão de Entorpecentes, que deveria ser composto pelo conjunto de órgãos e entidades da administração pública que exerciam atividades correlatas 32 . Entre os objetivos deste sistema, constava o de formular a Política Nacional de Entorpecentes através do Conselho Federal de Entorpecentes (CONFEN), seu órgão central.

Embora a atuação do CONFEN tenha privilegiado as atividades de repressão à produção, tráfico e consumo de drogas, a relevância de algumas iniciativas do órgão para o desenvolvimento de práticas de atenção ao consumo de álcool e outras drogas no cenário brasileiro é assinalada por Machado 31. Dentre as iniciativas ressaltam-se o apoio aos centros de referência em tratamento, pesquisa e prevenção na área de álcool e outras drogas, às comunidades terapêuticas e aos programas de redução de danos voltados para a prevenção da transmissão do HIV/AIDS entre UDI.

Os centros de referência começaram a ser criados na década de 1980, em sua maioria vinculados a universidades públicas. Esses centros voltavam-se ao desenvolvimento de ações de prevenção e assistência especializada ao uso abusivo de álcool e outras drogas, formação de profissionais qualificados para o atendimento de dependentes químicos e realização de estudos e pesquisas sobre o consumo de álcool e outras 
drogas, as ações de prevenção, o tratamento clínico e a redução de danos. Como a ênfase dos centros de referência estava na produção de conhecimento técnico-científico e formação de recursos humanos, muitos apresentavam uma oferta restrita de tratamento à população e funcionavam de forma pouco articulada com o sistema público de saúde 31 . Em contrapartida, os levantamentos epidemiológicos sobre o consumo de álcool e outras drogas na população brasileira e o estudo sobre as experiências européias de prevenção da AIDS entre UDI segundo a abordagem de redução de danos realizados pelos centros de referência exerceriam grande repercussão na política de drogas em décadas futuras.

As comunidades terapêuticas, em sua maioria instituições de natureza não governamental, começaram a ser criadas no país na década de 1970 e tiveram seu número expandido na década de 1990 31,33. O fenômeno de criação e expansão deste recurso terapêutico tem sido remetido à própria lacuna assistencial no setor público de saúde na área de álcool e outras drogas. O apoio do CONFEN a tais instituições deu-se mediante a deflagração de discussão sobre a normatização de seu funcionamento, objetivando promover a adequação técnica e ética da assistência prestada por esses estabelecimentos a usuários de álcool e outras drogas e às suas famílias.

Das iniciativas do CONFEN, a mais contundente para as práticas de atenção à saúde na área de álcool e outras drogas certamente foi seu posicionamento favorável, em 1994, à implementação no país de programas de redução de danos mediante a troca de seringas entre UDI 31 . Ao criminalizar práticas interpretadas como indução, incentivo, instigação, auxílio ou difusão do uso de drogas, a Lei no . 6.368/1976 instituía barreiras legais à implantação dos programas. Ademais, diversos setores da sociedade civil manifestavamse resistentes à abordagem da redução de danos.

Em 1998, o CONFEN foi extinto e transformado em Conselho Nacional Antidrogas (CONAD) 34. O Sistema Nacional de Prevenção, Fiscalização e Repressão de Entorpecentes foi transformado em Sistema Nacional Antidrogas (SISNAD), sendo mantidos, entretanto, os seus objetivos 35 . Neste rearranjo organizacional da estrutura política para enfrentamento das questões relacionadas às drogas, cria-se a Secretaria Nacional Antidrogas (SENAD), o órgão executivo do sistema. A declaração de guerra às drogas e o ideário de uma sociedade livre de drogas, reiterados durante a UNGASS, foram assimilados pela política brasileira na extensão "antidrogas" conferida às suas instituições e à política nacional de drogas.

Nesta nova estrutura político-organizacional, a proposição da Política Nacional Antidro- gas deveria ser feita pela SENAD e aprovada, acompanhada e atualizada pelo CONAD, órgão normativo e de deliberação coletiva do sistema. A participação do Ministério da Saúde na construção desta política efetua-se pela sua representação, por intermédio da Coordenação de Saúde Mental e do órgão de Vigilância Sanitária, no CONAD. O espaço institucional, que propicia o encontro entre representações de segmentos antidrogas e de atenção à saúde (governamental e não governamental), mostrou-se particularmente fecundo para a construção da política de drogas brasileira.

A partir do ano de 2000, podem ser observadas mudanças significativas no conteúdo da legislação brasileira sobre drogas. Por mais que ela permaneça alinhada ao discurso proibicionista, a atenção à saúde deixa de ser uma espécie de apêndice dessa política e se torna um tema cada vez mais relevante, ainda que persistam as contradições imanentes de uma estrutura político-organizacional militarizada para o enfrentamento das questões relacionadas às drogas. Uma importante mudança refere-se à distinção feita entre as atividades antidrogas e aquelas de prevenção, tratamento, recuperação e reinserção social, conferindo maior destaque a estas últimas 36 .

A Lei $n^{o} .10 .409 / 200237$ afirma que "o tratamento do dependente ou usuário será feito de forma multiprofissional e, sempre que possivel, com a assistência de sua família" (art. 12, § 1ㅇ). A referência às ações de redução de danos sociais e à saúde é feita pela primeira vez na legislação brasileira sobre drogas, cabendo ao Ministério da Saúde a sua regulamentação. Com vários de seus artigos vetados, a vigência desta lei não revogou por completo a Lei $n^{o}$. 6.368/1976, especialmente no que se refere à criminalização do porte de drogas ilícitas para consumo próprio.

A Política Nacional Antidrogas, instituída pelo Decreto $n^{o}$. 4.345/2002, retrata o uso indevido de drogas como uma ameaça séria e persistente à humanidade e à vida em sociedade, associando-o ao tráfico de drogas e a outros crimes e modalidades de violência 27 . O texto da política justifica a adoção de uma postura firme do Estado brasileiro de combate às drogas. Entre seus pressupostos básicos, destaca-se aquele que traduz a essência da perspectiva proibicionista em relação às drogas: "buscar, incessantemente, atingir o ideal de construção de uma sociedade livre do uso de drogas ilícitas e do uso indevido de drogas lícitas".

A despeito da forte influência do discurso proibicionista na formulação da Política Nacional Antidrogas, o acúmulo de experiências na implementação de programas de redução de danos 
na atenção à saúde de UDI e a pressão política exercida por profissionais e militantes na área contribuíram, de forma incisiva, para a permeabilidade dessa política ao enfoque da redução de danos 31 . Nesta perspectiva, a política de drogas brasileira aproxima discursos antagônicos. Por um lado, compartilha do discurso proibicionista legitimado por convenções internacionais quanto à redução da oferta e da demanda de drogas, mediante mecanismos de repressão e criminalização da produção, tráfico e porte de drogas ilícitas. Por outro lado, mostra-se aderente à abordagem de redução de danos.

Alguns pressupostos básicos da Política Nacional Antidrogas mostram-se de grande relevância para a construção de um modelo de atenção à saúde de usuários de álcool e outras drogas orientado pela lógica da redução de danos e compromissado com a garantia de seus direitos de cidadania. Assim, propõe-se reconhecer as diferenças entre usuário, a pessoa em uso indevido ou dependente e o traficante de drogas, considerando-se que esta distinção implica abordagens igualmente diferenciadas. Ademais, refere-se como necessário evitar a discriminação de indivíduos pelo fato de serem usuários ou dependentes de drogas e garantir o seu direito à atenção à saúde especializada.

Com a formulação da Política do Ministério da Saúde para Atenção Integral a Usuários de Álcool e outras Drogas, em 2003, admite-se o atraso histórico de inserção do uso prejudicial e/ou dependência do álcool e outras drogas na agenda da saúde pública ${ }^{28}$. Afirma-se a responsabilidade do Sistema Único de Saúde (SUS) em garantir atenção especializada aos usuários de álcool e outras drogas, até então contemplada predominantemente por instituições não governamentais, como as comunidades terapêuticas e os grupos de auto-ajuda e de ajuda mútua 33 . As diretrizes da política setorial de saúde prevêem a construção de uma rede de atenção a usuários de álcool e outras drogas valendo-se da implementação de Centros de Atenção Psicossocial Álcool e outras Drogas (CAPSad), que desempenham papel estratégico de ordenamento da rede em seu território de atuação, promovendo a articulação necessária entre os mais variados dispositivos comunitários sociais e de saúde para a integralidade da atenção e inclusão social de usuários e familiares acompanhados. Espera-se que o conteúdo das práticas de atenção aos usuários de álcool e outras drogas apresente embasamento na concepção ampliada de redução de danos e compromisso com os direitos de cidadania dos usuários de álcool e outras drogas.

A Política Nacional Antidrogas passou por um processo de realinhamento discursivo e o CO-
NAD aprovou, em 2005, a Política Nacional sobre Drogas 35 . Tal política se orienta para a redução da oferta (ações de prevenção e repressão ao tráfico de drogas ilícitas), a redução da demanda de drogas (prevenção, tratamento, recuperação e reinserção social) e a redução de danos. O enfoque da redução de danos aparece com força ainda maior nessa nova versão do texto da política, o que se faz notável naquela que talvez represente a mudança mais expressiva na trajetória discursiva das políticas públicas sobre drogas no Brasil: o discurso quanto ao ideal de uma "sociedade livre de drogas" 27 dá lugar ao ideal de uma "sociedade protegida do uso de drogas ilícitas e do uso indevido de drogas lícitas" 38.

Em relação à atenção à saúde, a Política Nacional sobre Drogas converge com a política do Ministério da Saúde ao reiterar o objetivo de implantar e pôr em prática uma rede de assistência a indivíduos com transtornos decorrentes do consumo de substâncias psicoativas. Admite-se que o tratamento, recuperação e reinserção social devem resultar da configuração de uma rede assistencial integrada e articulada, constituída por instituições governamentais e não governamentais do setor saúde e da assistência social: unidade básica de saúde, ambulatórios, Centro de Atenção Psicossocial, CAPsad, comunidades terapêuticas, grupos de auto-ajuda e ajuda mútua, hospitais gerais e psiquiátricos, hospital-dia, serviços de emergência, corpo de bombeiros, clínicas especializadas, casas de apoio e convivência e moradias assistidas.

Todavia, enquanto a política do Ministério da Saúde se posiciona em favor da construção de um modelo de atenção orientado pela lógica da redução de danos, a Política Nacional sobre Drogas admite e incentiva a coexistência de distintos modelos de atenção à saúde de usuários de álcool e outras drogas. A explicação para este esforço de conciliação entre racionalidades divergentes no que se refere ao conteúdo e à organização das práticas de saúde pode ser remetida ao conflito de interesses entre representantes dos diferentes modelos assistenciais no país. A este respeito, Machado ${ }^{31}$ assinala a participação das federações das comunidades terapêuticas e de profissionais e militantes de programas de redução de danos no processo de formulação da Política Nacional sobre Drogas. A política do Ministério da Saúde, inscrita no escopo da Política de Saúde Mental, contrapõe-se claramente ao modelo de atenção baseado na internação em hospital psiquiátrico ou em comunidade terapêutica tendo em vista a abstinência como meta exclusiva do tratamento.

No realinhamento discursivo da Política $\mathrm{Na}$ cional sobre Drogas, a estrutura político-orga- 
nizacional para enfrentamento das questões relacionadas às drogas, até então adjetivadas antidrogas, tiveram suas instâncias recentemente renomeadas. O Sistema Nacional Antidrogas passou a ser denominado Sistema Nacional de Políticas Públicas sobre Drogas 39; o Conselho Nacional Antidrogas, Conselho Nacional de Políticas sobre Drogas; e a Secretaria Nacional Antidrogas, Secretaria Nacional de Políticas sobre Drogas 40 . Os objetivos desta estrutura e de seus órgãos constituintes permanecem mantidos, embora seja perceptível uma transformação da compreensão da problemática das drogas e, conseqüentemente, das respostas do Estado diante dela.

A concepção do problema das drogas no discurso político emergente mostra-se cada vez mais ampliada. Nesse cenário, as drogas deixam de ser referidas como uma ameaça para serem reconhecidas como um problema social complexo a ser enfrentado com políticas públicas intersetoriais e políticas setoriais específicas, integrando de forma equilibrada estratégias nacionais e internacionais de repressão à produção e ao tráfico de drogas e de prevenção, atenção à saúde e reinserção social de usuários e dependentes de drogas.

A nova legislação brasileira sobre drogas - a Lei $n^{o}$. 11.343/2006 41, que revoga a Lei $n^{o}$. 10.409/2002 e a Lei $n^{\circ}$. 6.368/1976 - apresenta alguns avanços historicamente significantes e reveladores de um posicionamento político mais moderado em relação às drogas. Se por um lado as atividades de repressão à produção não autorizada e ao tráfico ilícito de drogas são acentuadas, com definição de novos crimes correlatos e o aumento das penalidades previstas; por outro lado, distingue a condição de usuários e dependentes de drogas e aborda, de forma mais extensiva que as leis anteriores, as atividades de prevenção ao uso indevido, atenção à saúde e reinserção social. Outra mudança expressiva refere-se ao estabelecimento de penas alternativas ao crime definido como porte de drogas para consumo pessoal.

A lógica da redução de danos apresenta-se transversal ao texto da nova legislação sobre drogas ${ }^{41}$. Assim, espera-se que as atividades de prevenção do uso indevido de drogas sejam orientadas para a redução dos fatores de vulnerabilidade e risco e para a promoção e o fortalecimento dos fatores de proteção. As atividades de atenção aos usuários e dependentes de drogas e suas famílias são definidas como aquelas que objetivam a melhoria da qualidade de vida e a redução dos riscos e danos associados ao uso de drogas. Para a reinserção social destes sujeitos, almeja-se a sua integração ou reintegração em redes sociais. Depreende-se dessas concepções em torno da atenção e reinserção social de usuários e dependentes de drogas a afirmação de um modelo de atenção coerente com a abordagem da redução de danos e com a promoção da cidadania. Em razão disso, esta legislação aponta para a reorientação de um modelo de atenção referenciado na abstinência como objetivo terapêutico exclusivo, na segregação sócio-familiar e na exclusão social de usuários e dependentes de drogas, que ainda se faz expressivo no país.

\section{Considerações finais}

As vicissitudes na trajetória discursiva das políticas públicas de drogas no Brasil decorrem de tensionamentos entre fatores externos e internos. Por um lado, o compromisso do país, mediante firmamento de acordos e convenções internacionais, com o combate ao tráfico e consumo de drogas ilícitas lhe confere um posicionamento de guerra às drogas com adoção de ações repressivas intensamente militarizadas. Em outra vertente, questionamentos internos sobre o conteúdo da legislação brasileira, particularmente no que se refere à abordagem do consumo de drogas lícitas e ilícitas como um problema de saúde pública - e não mero problema jurídico-policial - repercutiram na despenalização da conduta dos usuários 5 . Embora o porte de drogas ilícitas para consumo próprio ainda constitua um crime, admite-se o direito de cidadania aos usuários de drogas, inclusive o de fazer consumo com redução de danos sociais e à saúde e o de acesso aos bens e serviços de saúde pública.

A despeito dos avanços, há ainda muitas páginas a serem escritas e revisadas na história das políticas públicas brasileiras de drogas. No que se refere à atenção à saúde, a estruturação e fortalecimento de uma rede pública de saúde especializada na assistência a usuários de álcool e outras drogas e às suas famílias, centrada na atenção comunitária, orientada pela concepção ampliada de redução de danos e articulada com outras redes de serviços sociais e de saúde constitui, na atualidade, um importante desafio. Para a reorientação do modelo de atenção na área de álcool e outras drogas, o setor público de saúde aposta na implantação dos CAPSad. Dos 250 serviços propostos pela política do Ministério da Saúde, 182 foram implantados até outubro de 2008 42, mas para além deste quantitativo ressalta-se a relevância de compreensão dos saberes e das práticas de saúde em construção com base neste dispositivo assistencial estratégico. 


\section{Resumo}

O presente artigo tem por objetivo caracterizar os modelos de atenção à saúde de usuários de álcool e outras drogas existentes no contexto brasileiro. Para tanto, realizou-se uma análise do discurso de políticas públicas de drogas no Brasil a partir da década de 1970. Tal análise foi contextualizada por uma breve digressão sobre os principais posicionamentos políticos identificados entre países do mundo para o enfrentamento de questões relacionadas ao consumo de substâncias psicoativas. As políticas públicas brasileiras de drogas apresentam-se, a partir da presente década, permeáveis ao enfoque da redução de danos, repercutindo na reorientação do modelo de atenção à saúde. Conclui-se que a estruturação e o fortalecimento de uma rede de atenção integral aos usuários de álcool e outras drogas e às suas famílias, centrada na atenção comunitária, orientada pela concepção ampliada de redução de danos e articulada com outras redes de serviços sociais e de saúde constitui, na atualidade, um importante desafio à saúde pública.

Alcoolismo; Transtornos Relacionados ao Uso de Substâncias; Redução do Dano; Políticas Públicas

\section{Referências}

1. Teixeira CF. A mudança do modelo de atenção à saúde no SUS: desatando nós, criando laços. In: Teixeira CF, Solla JP, organizadores. Modelo de atenção à saúde: promoção, vigilância e saúde da família. Salvador: Edufba; 2006. p. 19-58.

2. Teixeira CF, Solla JP. Modelo de atenção à saúde no SUS: trajetória do debate conceitual, situação atual, desafios e perspectivas. In: Teixeira CF, Solla JP, organizadores. Modelo de atenção à saúde: promoção, vigilância e saúde da família. Salvador: Edufba; 2006. p. 129-67.

3. Bauer M, Aarts B. A construção do corpus: um princípio para a coleta de dados qualitativos. In: Bauer MW, Gaskell G, organizadores. Pesquisa qualitativa com texto, imagem e som: um manual prático. 2a Ed. Petrópolis: Editora Vozes; 2003. p. 39-63.

4. Araújo MR, Moreira FG. Histórias das drogas. In: Silveira DX, Moreira FG, organizadores. Panorama atual de drogas e dependências. São Paulo: Editora Atheneu; 2006. p. 9-14.

5. Ribeiro MM. Aspectos legais. In: Silveira DX, Moreira FG, organizadores. Panorama atual de drogas e dependências. São Paulo: Editora Atheneu; 2006. p. 469-76.

6. Canty C, Sutton A, James S. Strategies for community-based drug law enforcement: from prohibition to harm reduction. In: Stockwell T, Gruenewald PJ, Toumbourou JM, Loxley W, editors. Preventing harmful substance use: the evidence base for policy and practice. Chichester: John Wiley \& Sons; 2005. p. 225-36.

7. Tammi T, Hurme T. How the harm reduction movement contrasts itself against punitive prohibition. Int J Drug Policy 2007; 18:84-7.
8. Ritter AL, Cameron J. A systematic review of harm reduction. Fitzroy: Turning Point Alcohol and Drug Centre; 2005. (DPMP Monograph Series, 6).

9. Wodak A. Harm reduction is now the mainstream global drug policy. Addiction 2009; 104:343-5.

10. Weatherburn D. Dilemmas in harm minimization. Addiction 2009; 104: 335-9.

11. Ball AL. HIV, injecting drug use and harm reduction: a public health response. Addiction 2007; 102:684-90.

12. Perduca M. Vamos criminalizar a proibição! In: Acselrad G, organizador. Avessos do prazer: drogas, AIDS e direitos humanos. 2a Ed. Rio de Janeiro: Editora Fiocruz; 2005. p. 51-63.

13. MacMaster SA. Harm reduction: a new perspective on substance abuse services. Soc Work 2004; 49:356-63.

14. Ribeiro MM, Araújo MR. Política mundial de drogas ilícitas: uma reflexão histórica. In: Silveira DX, Moreira FG, organizadores. Panorama atual de drogas e dependências. São Paulo: Editora Atheneu; 2006. p. 457-68.

15. Morais PCC. Drogas e políticas públicas [Tese de Doutorado]. Belo Horizonte: Universidade Federal de Minas Gerais; 2005.

16. Galduróz JCF, Noto AR, Nappo SA, Carlini EA. Uso de drogas psicotrópicas no Brasil: pesquisa domiciliar envolvendo as 107 maiores cidades do país - 2001. Rev Latinoam Enferm 2005, 13 N Esp: $888-95$. 
17. Carlini EA, Galduróz JC, Noto AR, Carlini CM, Oliveira LG, Nappo SA, et al. II levantamento domiciliar sobre o uso de drogas psicotrópicas no Brasil: estudo envolvendo as 108 maiores cidades do país - 2005. São Paulo: Centro Brasileiro de Informações sobre Drogas Psicotrópicas, Universidade Federal de São Paulo; 2006.

18. Fonseca EM, Bastos FI. Políticas de redução de danos em perspectiva: comparando as experiências americana, britânica e brasileira. In: Acselrad G, organizador. Avessos do prazer: drogas, AIDS e direitos humanos. 2a Ed. Rio de Janeiro: Editora Fiocruz; 2005. p. 289-310.

19. Marlatt GA. Redução de danos: estratégias práticas para lidar com comportamentos de alto risco. Porto Alegre: Editora Artmed; 1999.

20. Reghelin EM. Redução de danos: prevenção ou estímulo ao uso indevido de drogas injetáveis. São Paulo: Revista dos Tribunais; 2002.

21. Gossop M. Maintenance treatments across countries. Addiction 2008; 103:1493-4.

22. Emmanuelli J, Desenclos J. Harm reduction interventions, behaviours and associated health outcomes in France, 1996-2003. Addiction 2005; 100:1690-700.

23. Kellogg SH. On "gradualism" and the building of the harm reduction-abstinence continuum. J Subst Abuse Treat 2003; 25:241-7.

24. Beek IV. Harm reduction: an ethical imperative. Addiction 2009; 104:342-3.

25. Fiore M. A medicalização da questão do uso de drogas no Brasil: reflexões acerca de debates institucionais e jurídicos. In: Venâncio RP, Carneiro $\mathrm{H}$, organizadores. Álcool e drogas na história do Brasil. São Paulo: Editora Alameda/Belo Horizonte: PUCMinas; 2005. p. 257-90.

26. Karam ML. Legislação brasileira sobre drogas: história recente - a criminalização da diferença. In: Acselrad G, organizador. Avessos do prazer: drogas, AIDS e direitos humanos. 2a Ed. Rio de Janeiro: Editora Fiocruz; 2005. p. 155-64.

27. Secretaria Nacional Antidrogas. Política nacional antidroga. Brasília: Secretaria Nacional Antidrogas; 2002.

28. Secretaria de Atenção à Saúde, Ministério da Saúde. A política do Ministério da Saúde para atenção integral a usuários de álcool e outras drogas. 2a Ed. Brasília: Ministério da Saúde; 2004.

29. Lei $n^{\circ}$. 5.726 de 29 de outubro de 1971. Dispõe sobre medidas preventivas e repressivas ao tráfico e uso de substâncias entorpecentes ou que determinem dependência física ou psíquica e dá outras providências. Diário Oficial da União 1971; 1 nov.

30. Lei no 6.368 de 21 de outubro de 1976. Dispõe sobre medidas de prevenção e repressão ao tráfico ilícito e uso indevido de substâncias entorpecentes ou que determinem dependência física ou psíquica, e dá outras providências. Diário Oficial da União 1976; 22 out.

31. Machado AR. Uso prejudicial e dependência de álcool e outras drogas na agenda da saúde pública um estudo sobre o processo de constituição da política pública de saúde do Brasil para usuários de álcool e outras drogas [Dissertação de Mestrado]. Belo Horizonte: Universidade Federal de Minas Gerais; 2006.
32. Decreto $n^{\circ}$. 85.110 de 2 de setembro de 1980. Institui o Sistema Nacional de Prevenção, Fiscalização e Repressão de Entorpecentes. Diário Oficial da União 1980; 3 set.

33. Carvalho DBB, coordenador. Mapeamento das instituições governamentais e não governamentais de atenção às questões relacionadas ao consumo de álcool e outras drogas no Brasil - 2006/2007: Relatório. Brasília: Secretaria Nacional Antidrogas; 2007.

34. Medida Provisória no ${ }^{\circ}$ 1.689-2 de 29 de julho de 1998. Altera a Lei no. 9.649, de 27 de maio de 1998, que dispõe sobre a organização da Presidência da República e dos Ministérios, e dá outras providências. Diário Oficial da União 1998; 30 jul.

35. Decreto $n^{\circ} .2 .632$ de 19 de junho de 1998. Dispõe sobre o Sistema Nacional Antidrogas, e dá outras providências. Diário Oficial da União 1998; 22 jun.

36. Decreto $\mathrm{n}^{\mathrm{o}}$. 3.696 de 21 de dezembro de 2000. Dispõe sobre o Sistema Nacional Antidrogas, e dá outras providências. Diário Oficial da União 2000; 22 dez.

37. Lei $n^{\circ}$. 10.409 de 11 de janeiro de 2002. Dispõe sobre a prevenção, o tratamento, a fiscalização, o controle e a repressão à produção, ao uso e ao tráfico ilícitos de produtos, substâncias ou drogas ilícitas que causem dependência física ou psíquica, assim elencados pelo Ministério da Saúde, e dá outras providências. Diário Oficial da União 2002; 14 jan.

38. Conselho Nacional Antidrogas. Política nacional sobre drogas. Brasília: Conselho Nacional Antidrogas; 2005.

39. Decreto $n^{\circ}$. 5.912 de 27 de setembro de 2006. Regulamenta a Lei no. 11.343 de 23 de agosto de 2006, que trata das políticas públicas sobre drogas e da instituição do Sistema Nacional de Políticas Públicas sobre Drogas - SISNAD, e dá outras providências. Diário Oficial da União 2006; 28 set.

40. Lei $n^{\circ}$. 11.754 de 23 de julho de 2008. Acresce, altera e revoga dispositivos da Lei $\mathrm{n}^{\circ}$. 10.683, de 28 de maio de 2003, cria a Secretaria de Assuntos Estratégicos da Presidência da República, cria cargos em comissão; revoga dispositivos das Leis nos. 10.869 de 13 de maio de 2004 e 11.204 de 5 de dezembro de 2005; e dá outras providências. Diário Oficial da União 2008; 24 jul.

41. Lei $\mathrm{n}^{\mathrm{o}}$. 11.343 de 23 de agosto de 2006. Institui o Sistema Nacional de Políticas Públicas sobre Drogas - SISNAD; prescreve medidas para prevenção do uso indevido, atenção e reinserção social de usuários e dependentes de drogas; estabelece normas para repressão à produção não autorizada e ao tráfico ilícito de drogas; define crimes e dá outras providências. Diário Oficial da União 2006; 24 ago.

42. Ministério da Saúde. Saúde Mental em Dados - 5, ano III, $\mathrm{n}^{\circ}$. 5. Informativo eletrônico. http:// www.ccs.saude.gov.br/saude_mental/pdf/smDa dos/2008_SMD_05.pdf (acessado em 23/Dez/ 2008).

Recebido em 02/Fev/2009

Versão final reapresentada em 27/Abr/2009

Aprovado em 22/Jun/2009 